ARTICLE HISTORY: Received: June 3, 2021 Accepted: July 25, 2021 Published: August 3, 2021

ФОРМЫ И ВИДЫ МЕЖДУНАРОДНОГО АУТСОРСИНГА

Комаров Сергей Михайлович

Тульский государственный университет, аспирант.

Тел. 8 (4842) 516-337

\title{
FORMS AND TYPES OF INTERNATIONAL OUTSOURCING
}

\author{
Komarov Sergey Mikhailovich \\ Tula State University, postgraduate student. \\ Tel. 8 (4842) 516-337
}

\begin{abstract}
Аннотация. Статья представляет собой уточняющее исследование на основе результатов ранее проведённых поисковых исследований автора. Рассматриваются виды и формы международного аутсорсинга, отражающие внутреннюю структуру международного аутсорсинга и взаимодействия между участниками международного аутсорсинга. Автор предлагает новые классификации видов и форм международного аутсорсинга.

Ключевые слова: внешний международный аутсорсинг, внутренний международный аутсорсинг, совместный международный аутсорсинг, международный аутсорсинг с односторонней координацией, международный аутсорсинг с двусторонней координацией, международный аутсорсинг с разделением расходов на управление валютным риском между участниками, международный аутсорсинг без разделения расходов на управление валютным риском между участниками.

Abstract. The article is a clarifying study based on the results of the author's earlier exploratory research. The types and forms of international outsourcing are considered, reflecting the internal structure of international outsourcing and interaction between participants in international outsourcing. The author proposes new classifications of types and forms of international outsourcing.

Keywords: external international outsourcing, internal international outsourcing, joint international outsourcing, international outsourcing with unilateral coordination, international outsourcing with bilateral coordination, international outsourcing with cost sharing for currency risk management between participants, international outsourcing without sharing the costs of currency risk management between participants.
\end{abstract}

Международный аутсорсинг позволяет усилить уникальную специализацию компаний на международном рынке. Однако на его развитие оказывают влияние различные факторы. Эти факторы разняться в зависимости от особенностей страны, в которой осуществляется международный аутсорсинг. Влияние различных факторов на развитие международного аутсорсинга побуждает исследовать его, с целью установления интенсивности влияния факторов на различные его виды. Необходимость управления данными факторами, порождает новые формы международного аутсорсинга, отражающие взаимодействие между участниками экономической системы.

На сегодняшний день основным фактором оказывающим влияние на развитие международного аутсорсинга в России является валютный риск. Кирил Гусев, утверждал, что среди прочих причин снижение привлекательности России для прямых иностранных инвестиций вызвано обвальным падением курса рубля в 2014 г. ${ }^{1}$ Автор установил связь между показателями, характеризующими международный аутсорсинг и динамикой курса валюты. ${ }^{2}$ В работе автора «Экономический валютный риск в международном аутсорсинге на примере компаний входящих в машиностроительный кластер калужской области за период с 2012 по 2016 год» показано воздействие косвенного экономического валютного риска на компании участвующие в

1 Гусев Кирилл: «Иностранные инвестиции, курс рубля и структурная перестройка российской экономики»/Аналитическая записка №5, 2015 (№5)/ ФГБУН ИНСТИТУТ ЕВРОПЫ РОССИЙСКОЙ АКАДЕМИИ НАУК;

${ }^{2}$ Комаров С.М.«Исследование взаимосвязи международного аутсорсинга с показателями промежуточного импорта и колебаниями курса валют»/ Петербургский экономический журнал: научно-практический рецензируемый журнал/ Санкт-Петербургский государственный институт кино и телевидения. - СПб., 2019.- № 4. c. $117-125$ 
международном аутсорсинге. ${ }^{3}$ Также автор утверждает, что в период с 2011 по 2012 год колебания курса валют оказали воздействие на действующие на территории России организации с участием иностранного капитала. ${ }^{4}$

Рассмотрение валютного риска в качестве основного фактора формирования и развития международного аутсорсинга позволяет осознать сущность этого экономического процесса и выявить его внутреннюю структуру. Управление валютным риском промышленных предприятий предполагает необходимость рассмотрения международного аутсорсинга в виде комплексного структурного процесса, включающего три основные составляющие:

- внешний международный аутсорсинг. Размещение зарубежными компаниями отдельных производственных функций на предприятиях, функционирующих на территории России;

- внутренний международный аутсорсинг. Размещение отечественными компаниями отдельных производственных функций на предприятиях, находящихся на территории других государств;

- совместный международный аутсорсинг. Осуществление совместной производственной деятельности на основе реализации партнерских отношений и выполнением различных производственных функций для получения конечного продукта.

Таким образом, основываясь на внутренней структуре процесса международного аутсорсинга, в зависимости от размещения производственных функций можно выделить внешний, внутренний и совместный международный аутсорсинг.

Сущность влияния валютного риска на формирование и развитие международного аутсорсинга представлена на (рис. 1).

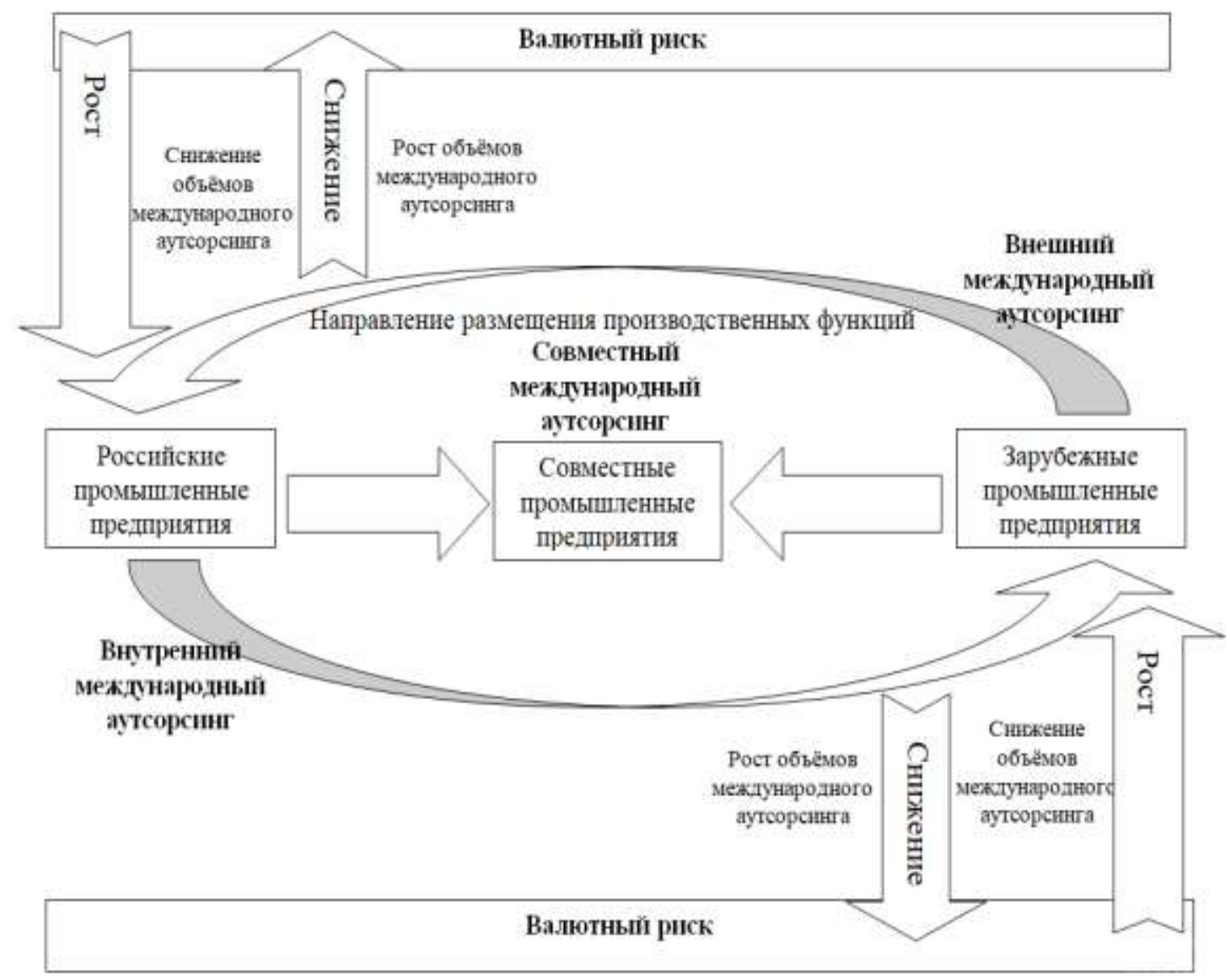

Рис. 1 - Сущность влияния валютного риска на формирование и развитие международного аутсорсинга.

3 Комаров С. М. «Экономический валютный риск в международном аутсорсинге на примере компаний входящих в машиностроительный кластер калужской области за период с 2012 по 2016 год»./VII International scientific conference «problems and prospects of development of economy and management». (г. Prague, 2019 г.).

${ }^{4}$ Комаров С.М. «Влияние экономического фактора спекулятивного валютного риска на международный аутсорсинг» «Научные исследования и разработки. Экономика Фирмы», Том 9, № 1. 2020. с.27-37. 
Сущность влияния валютного риска на формирование и развитие международного аутсорсинга заключается в том, что в зависимости от волатильности национальной валюты изменяется интенсивность формирования и развития различных видов международного аутсорсинга.

Установление сущности и внутренней структуры международного аутсорсинга, как комплексного экономико-организационного процесса позволяет существенно повысить эффективность цепочки создания конечной ценности и рационально распределять валютный риск между участниками международного аутсорсинга.

Необходимость управления валютным риском порождает новые формы международного аутсорсинга отличающиеся по направлению координации деятельности аутсорсера и отношением организаций участвующих в цепочке создания конечной ценности к разделению расходов на управление возникающего риска (Рис. 2). Данные формы отражают взаимодействия, которые возникают при внешнем, внутреннем и совместном международном аутсорсинге.

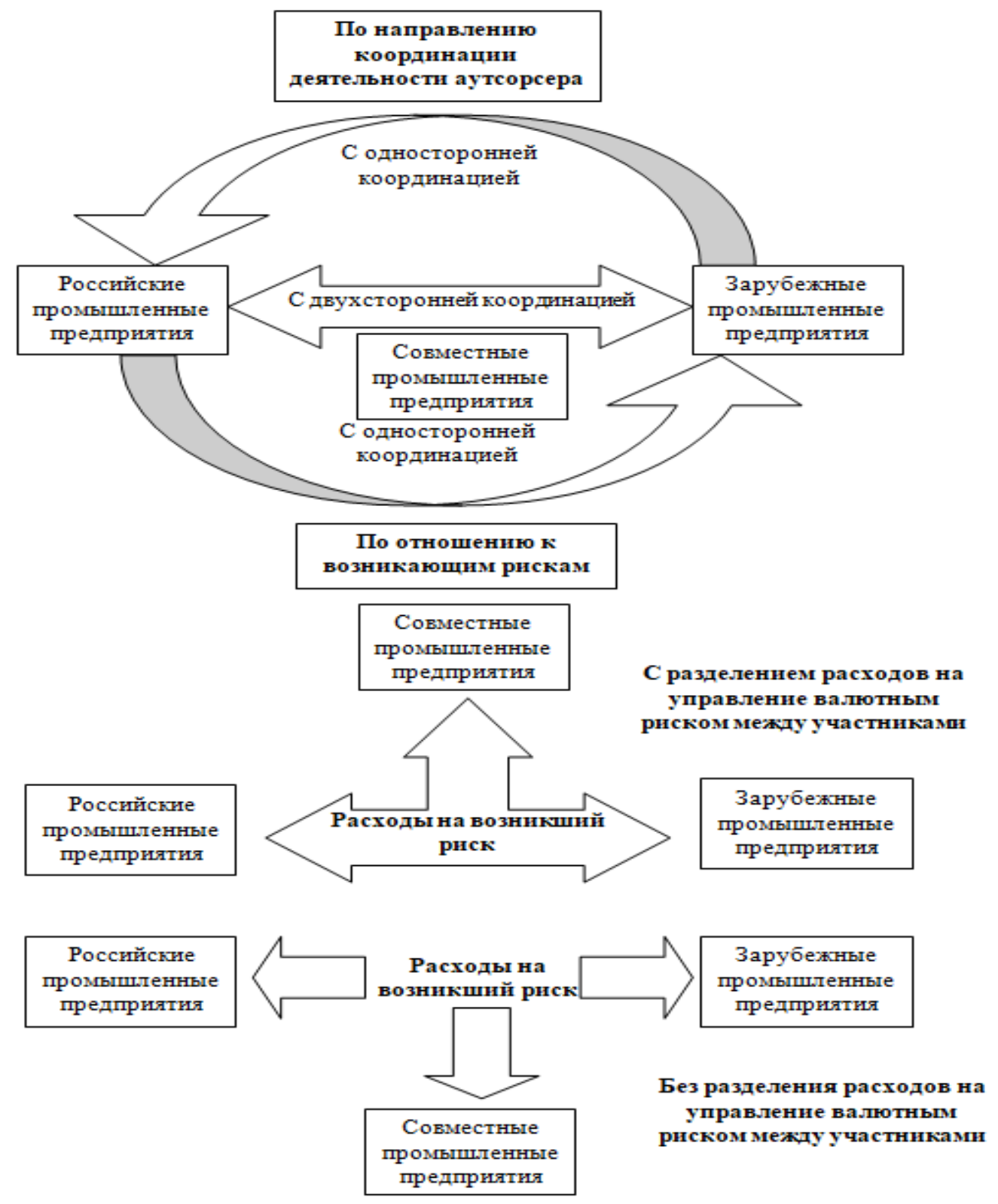

Рис. 2 - Авторская классификаџия форм аутсорсинга.

Таким образом, на сегодняшний день автор выделяет внешний, внутренний и совместный виды международного аутсорсинга. Также автор выделяет формы международного аутсорсинга с односторонней и двусторонней координацией, а также с разделением расходов на управление валютным риском и без разделения расходов на управление валютным риском. 


\section{Список литературы}

1. Гусев Кирилл: «Иностранные инвестиции, курс рубля и структурная перестройка российской экономики»/Аналитическая записка №5, 2015 (№5)/ ФГБУН ИНСТИТУТ ЕВРОПЫ РОССИЙСКОЙ АКАДЕМИИ НАУК;

2. Комаров С. М. «Влияние экономического фактора спекулятивного валютного риска на международный аутсорсинг» «Научные исследования и разработки. Экономика Фирмы», Том 9, № 1. 2020.

3. Комаров С. М. «Исследование взаимосвязи международного аутсорсинга с показателями промежуточного импорта и колебаниями курса валют»/ Петербургский экономический журнал: научнопрактический рецензируемый журнал/ Санкт-Петербургский государственный институт кино и телевидения. СПб., 2019.- № 4;

4. Комаров С. М. «Экономический валютный риск в международном аутсорсинге на примере компаний входящих в машиностроительный кластер калужской области за период с 2012 по 2016 год»./VII International scientific conference «problems and prospects of development of economy and management». (г. Prague, 2019 г.).

\section{References}

1. Gusev Kirill: "Foreign investments, the ruble exchange rate and structural restructuring of the Russian economy"/ Analiticheskaya zapiska №5, 2015 (№5)/ FGBUN INSTITUT YEVROPY ROSSIYSKOY AKADEMII NAUK;

2. Komarov S. M. «Vliyaniye ekonomicheskogo faktora spekulyativnogo valyutnogo riska na mezhdunarodnyy autsorsing» «Nauchnyye issledovaniya i razrabotki. Ekonomika Firmy», Vol. 9, № 1. 2020.

3. Komarov S.M. "Study of the relationship of international outsourcing with indicators of intermediate imports and currency fluctuations"/ Peterburgskiy ekonomicheskiy zhurnal: nauchno-prakticheskiy retsenziruyemyy zhurnal/ Sankt-Peterburgskiy gosudarstvennyy institut kino i televideniya. - SPb., 2019.- № 4;

4. Komarov S.M. "Economic currency risk in international outsourcing on the example of companies included in the machine-building cluster of the Kaluga region for the period from 2012 to 2016"./VII International scientific conference "problems and prospects of development of economy and management». (Prague, 2019). 